\title{
XXX. The absolute wave-length of light
}

\section{Louis Bell}

To cite this article: Louis Bell (1888) XXX. The absolute wave-length of light, Philosophical Magazine Series 5, 25:155, 245-263, DOI: 10.1080/14786448808628181

To link to this article: http://dx.doi.org/10.1080/14786448808628181

曲 Published online: 29 Apr 2009.

Submit your article to this journal $2 \pi$

Џ Article views: 4

Q View related articles $₫$ 
LONDON, EDINBURGH, AND DUBLIN

\title{
PHILOSOPHICAL MAGAZINE
}

\author{
AND \\ JOURNAL OF SCIENCE.
}

[FIFTH SERIES.]

$A P R I L 1888$.

XXX. The Absolute Wave-length of Light. By LouIs BeLL, Fellow in Physics in Johns Hopkins University*.

7 THIS paper contains the final results of the research partially reported in this Journal for March 1887. In view of the wide discrepancies in the value of this physical constant as determined by various observers and methods, it has seemed desirable to give in brief the history of the subject, and to discuss critically certain portions of the investigation which have proved stumbling-blocks in the past. I refer particularly to the verification of the standards of length employed, and to those errors of ruling in the gratings which may, and usually do, produce errors in the result obtained.

The first portion of this paper will be devoted to the methods and results of the pioneers in this work, and the methods, apparatus, and standards of length employed in the present investigation.

The second portion will contain the details of the experimental work, together with a discussion of the final results and those questions of theoretical and practical interest which arise in connexion with the work of recent experimenters. With this preliminary notice is presented the first half of the paper.

\section{Historical.}

Fraunhofer's first paper on the lines which bear his name marks a new era in the science of optics. Up to that point any careful study of spectra had been impossible for lack of

* Communicated by the Author.

Plitl. Mug. S. 5. Vol. 25. No. 155. April 1888. 
definite standards of reference, and because the apparatus was as yet very defective. Fraunhofer's research, "Bestimmung des Brechungs- und Farben-zerstreuungs-Vermögens verschiedener Glasarten," was presented to the Munich Academy of Sciences in 1814, and was published in the fifth volume of the Denkschriften. It then became possible to study in detail the properties of rays of definite position, and the work was taken up almost immediately. Almost the first step was to determine the wave-lengths of prominent points in the solar spectrum ; and, as is well known, Fraunhofer himself took it, determining the wave-lengths corresponding to his lines B, C, D, E, F, G, H. As there seems to have been (noticeably in Verdet's papers) some confusion concerning his papers on this subject, it may be well here to clear the matter up.

Fraunhofer's first paper dealing with the subject was presented to the Munich Academy in 1821. It is entitled, "Nene Modifikation des Lichtes durch gegenseitige Einwirkung und Beugung der Strahlen, und Gesetze derselben," and was printed in the eighth volume of the Denkschriften. It is of considerable length, and deals with various diffraction phenomena, but its chief interest lies in the wave-length measurements made with wire gratings. The experiments made with ten of these are given in detail, and are remarkably carefal and consistent. The gratings were quite various, the wires being from 0.04 to 0.6 millim. in thickness, and the grating-space, as ordinarily measured, from 0.0528 to 0.6866 millim. From these proportions it is evident enough that the spectra must have been imperfect; but, in spite of this, Fraunhofer obtained results which agreed remarkably well with each other. The wave-lengths of $D$, as obtained from the above-mentioned ten gratings, were as follows, reduced to millimetres :-

$\begin{array}{ll} & \text { millim. } \\ \text { (1) } & 0.0005891 \\ \text { (2) } & 0.0005894 \\ \text { (3) } & 0 \cdot 0005891 \\ \text { (4) } & 0.0005897 \\ \text { (5) } & 0.0005885\end{array}$

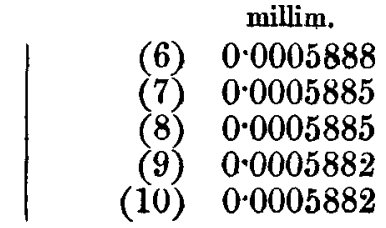

The mean value adopted was 0.0005888 millim., which, considering the gratings, and the fact that most of the angles of deviation were less than $1^{\circ}$, is certainly remarkably accurate. It should be noted, too, that the finer gratings (1) to (4) gave even better results.

A brief discussion of this paper appeared in the seventy- 
third volume of Gilbert's Annalen, and a French reprint in Schumacher's Astronomische Abhandlungen (ii. p. 46).

Fraunhofer's second and more complete paper appeared in 1823 in Gilbert's Annalen (lxxiv. p. 337). Its title is, "Kurzer Bericht von den Resultaten neuerer Versuche über die Gesetze des Lichts, und die Theorie derselben." This paper gives a detailed account of his experiments with two glass gratings. Of these, the grating-spaces were respectively 0.0033 and 0.0160 millim. The former was apparently much the better, and upon it Fraunhofer based his final result, which for D was 0.0005886 millim., while the experiments with the coarser grating gave 0.0005890 millim. These values apply quite certainly to the mean of the two D lines, and not, as bas been sometimes supposed, to one of them alone.

The experimental work with these glass gratings was much better than with the previous wire ones, since the angular deflections were very much larger, and the gratings themselves were susceptible of far more exact measurement. But at best they were but indifferent instruments, and the terminal lines were so bad that they had to be retraced before the gratingspace could be determined. So, between poor gratings and indifferent standards of length, Fraunhofer's determination of absolute wave-length left very much to be desired. However, nothing much better could be accomplished until the art of making gratings was very much improved; and it was not until Nobert's gratings became tolerably well known that any serious attempt was made to improve on Fraunhofer's results. From time to time various investigators worked at the problem, both with Nobert's earlier gratings and by utilizing various interference phenomena. When, however, the great investigations of Bunsen and Kirchboff revolutionized spectroscopic work and emphasized its great importance, the attention of scientific men was called to the need for accurate measurements; and for half a dozen years investigators were active, and Mascart, Ditscheiner, and Angström appeared on the field almost simultaneously. Each published a paper in 1864, and of these that of Mascart is probably the most accurate and painstaking, though now it is quite certain that the values he obtained were considerably too small. He employed four or five of Nobert's gratings, and instead of placing the grating perpendicular to either the collimator or the observingtelescope, used it in the position of minimum deviation, that is to say, so that the plane of the grating should bisect the angle formed by the incident and diffracted rays. This position has certain advantages; but as the experimentation is rather more difficult than in the ordinarv position, the 
method appears to be of somewhat questionable utility. It avoids, to be sure, the necessity of placing the grating normal to the axis of either telescope; but as there is very little trouble in making this adjustment with a high degree of accuracy, and keeping it throngh a series of measurements, the gain is by no means considerable. Aside from this question, Mascart's spectrometer read only to five seconds; and while his results with different gratings agree very well individually, they are certainly collectively in error by quite a large amount, very possibly owing to bad standards of length.

It is a fact to be noted in discussing all these earlier wavelength determinations, that sufficient attention was not paid to the measurement and study of the gratings-by all odds the most difficult part of the problem. The angular measurements of any one of the above investigators were good enough to have given very exact results had they been combined with proper investigations of the grating-spaces. As most of Nobert's gratings were small and by no means accurately ruled, there was peculiar need of care in measuring them; and when one considers that the defining-lines on most standards of length are far from being good, it is clear that the chances of error were numerous. In Angström's first paper he even relied on the grating-space assigned by the maker. Ditscheiner employed a grating which had belonged to Fraunhofer himself; but the number of spaces was uncertain, and this led to a large error, which he corrected, in part, in a supplementary paper some years later. Ditscheiner's principal paper was published in 1866 ; and was followed in 1868 by an elaborate discussion of the whole problem by Van der Willigen, whose paper is valuable mainly for a particularly elaborate review of sources of error. Like his predecessors, he used Nobert's gratings; but as the construction of his spectrometer confined his angular measurements to the deviation on one side of the normal, their accuracy may be somewhat open to question ; while his standard of length was anything but reliable, as it was a glass scale only three centimetres long, and the only assurance of its accuracy was the certificate of the maker that it was " très exacte" at $50^{\circ}$ Centigrade. For one or both of the above reasons, Van der Willigen's results were larger than any which have been obtained, before or since his time.

In the same year appeared Angström's great research which has so long served as the standard in all questions of wavelength. It is hard to say too much of the conscientious and painstaking experiments on which his results were based ; and any want of accuracy in the final result was due to no lack of skill or care on his part, but rather to the imperfect instruments with which he was obliged to work. Like every one 
before him, he used Nobert's gratings; and in spite of the fact that, like all Nobert's gratings, they gave very imperfect definition and showed numerous "ghosts," his results were more than usually consistent. But, in spite of all Ångström's care, the event has shown that his wave-lengths are in error by as much as one part in seven or eight thousand, mainly through an error in the assumed values of his standards of length. Angström measured his gratings by means of a dividing-engine, the screw of which was very exactly determined by comparisons resting on the Upsala metre, which, in turn, had been compared by M. Tresca with the prototype of the Conservatoire des arts et métiers. Had this comparison given the correct value of the Upsala metre, Angström's wave-lengths would have been very nearly exact except for corrections due to errors of ruling in the gratings.

After Angström's research the question of absolute wavelength was not seriously raised for ten years; when Mr. C.S. Peirce, under the auspices of the United States Coast Surrey, again attacked the problem, armed with Rutherfurd gratings far superior to those used in any previous research. No official report of his very elaborate and exhaustive experiments has ever been published, save a very brief preliminary report in the American Journal of Science in 1879. Such of his results as have been made in any way public will be discussed in the experimental part of the present paper.

Meanwhile Thalén, who so efficiently aided Ångström in his work, had taken up the part of it left uncompleted by the latter's death; and in his paper, Sur le Spectre du Fer, published at Upsala in 1885, discussed the corrections which must be applied to Angström's values by reason of the error in the Upsala metre. It seems that, through the experiments of Professor Lindhagen, Angström became aware, as early as 1872 , that the assumed value of his standard was considerably too small. His death prevented his verification of M. Lindhagen's results, and nothing further was done till Thalén took up the work. Tresca's comparisons had obtained for the length of the Upsala metre at $0^{\circ} 999.81$ millim. But the very exact experiments of M. Lindhagen have shown the above to be somewhat too small, and that the correct value is 999.94. This difference makes, of course, a marked error in the wave-lengtbs based on Tresca's results. Applying the appropriate correction, the wave-length of $\mathrm{E}$, the line most carefully determined by Angström, becomes

instead of the original

$5269 \cdot 80$, 
This final result of Ångström is certainly entitled to con... siderable respect, and seems to be subject only to those corrections which may be due to irregularities in the gratings. These were, however, so poor compared with the gratings of today that such corrections would necessarily be of uncertain magnitude.

At all events it is quite sure that, of the wave-length determinations made up to 1880 , those of Peirce, and sngström corrected by Thalén, are by all odds the best. Of the two Peirce's is probably the better, by reason of better gratings ; but his work will be discussed in another part of this paper in connexion with the very recent works of Müller and Kenpf and Kurlbaum, which merit more extended study than would be in place at this point.

A tolerably complete bibliography of the subject up to date is annexed. Many of the papers are of little except historical value; but they will at least exhibit the various methods employed, and the growth of exact experimentation.

1821. Fraunhofer.-Denkschr. d. Alad. d. Wiss, zu München, viii. Heft ii. p. 38. "Neue Modifikation des Lichtes durch gegenseitige Einwirkung und Beugung der Strahlen, und Gesetze derselben."

1823. Fraunhofer.-Schumncher's Astronomische Alhandlungen, ii. p. 46.

1823. Fraunhofer-Gilbert's Annalen, lxxiv. p. 337. "Kurzer Bericht von den Resultaten neuerer Versuche über die Gesetze des Lichtes, und die Theorie derselben."

1835. Schwerd.-Die Beugungserschcinungen. (Mannheim.)

1849. Stokes.-Athenæum, No. 1143; Inst. xvii. p. 368. "On the Determination of the Wave-length corresponding with any Point of the Spectrum."

1851. Nobert.--Proc. Roy. Soc. vi. p. 43 ; Phil. Mag. [4] i. p. 570. "Description and Purpose of the Glass Plate which bears the Inscription-Longitudo et celeritas undularum lucis cum in aere tum in vitro."

1851. Nobert.-Pogg. Ann. lxxxv. p. 83. "Ueber eine Glasplatte mit Theilungen zur Bestimmung der Wellenlänge und relativen Geschwindigkeit des Lichts in der Luft und im Glase."

1852. Drobisch.-Pogg. Ann. Ixxxviii. p. 519. "Ueber die Wellenlänge und Oscillationszahlen der farbigen Strahlen im Spectrum."

1853. Esselbach.-Berlin Moratsber. p. 757. "Ueber die Messung der Wellenlänge des ultravioletten Lichts."

1856. Esselbach.-Pogg. Ann. xcviii. p. 513; Ann. de Chim. et de Phys. [3] 50. p. 121." "Eine Wellenmessung im Spectrum jenseits des Violetts."

1856. Eisenlohr.-Pogg. Ann. xeviii. p. 353, xcix. p. 159; Ann. de Clim. et de Phys. [3] xlix. p. 504. "Die brechbarsten oder unsichtbaren Lichtstrahlen in Beugungspectrum und ihre Wellenläıge."

1863. Müller.-Pogg. Ann. cxviii. p. 641. "Bestimmung der Wellenlänge einiger heller Spectrallinien. '

1863. Mascart. -C. R. Ivi. p. 138. "Détermination de longueur d'onde de la raie A."

1864. Mascart.C. R. lviii. p. 1111. "Détermination des longueurs d'onde des rayons lumineux et des rayons ultrariolets." 
1864. Mascart.-Ann. de l'Ecole Normale, i. p. 219. "Recherches sur la détermination des longueurs d'onde.

1864. Bernard.-Mondes, v, p. 181. "Théorie des bandes d'interférence ..... Longueur d'onde de la raie A.".....

1864. Stefan.-Ber. d. Wien. Acad. 50. Heft ii. p. 31; Pogg. Ann. cxxii. p. 631. "Ueber die Dispersion des Lichtes durch Drehung der Polarizations-ebene im Quarz."

1864. Bernard.-C. R. lviii. p. 1153 ; lix. p. 352. "Mémoire sur la détermination des longueurs d'onde des raies du spectre solaire au moyen des bandes d'interférence."

1864. Ditscheiner.-Ber.d. Wien. Acad.50. Heft ii. p. 296, "Bestimnung der Wellenlänge der Fraunhofer'schen Linien des Sonnenspectrums."

1864. Angström.-Pogg. Ann. cxxiii. p. 489 ; Gfvers. af Förhandl. (1863) p. 41. "Neue Bestimmung der Läng"e der Lichtwellen nebst eine Methode auf Optischen Wege die fortschreitende Bewegung des Sonnensystems zu bestimmen.

1866. Ditscheiner.--Ber. der Wien. Acad. 52. Heft ii.p. 289. "Eine absolute Bestimmung der Wellenlänge der Fraunhofer'schen D Linien."

1868. Mascart.-Ann, de l'Ecole Normale, iv, p. 7. "Recherches sur la détermination des longueurs d'onde."

1868. Mascart.-Ann. de Chim. et de Phys. [4] xiii. p. 186. "Note sur différents travaux relatifs aux longneurs d'onde."

1868. Van der Willigen.-Arch. du Musée Teyler, i. pp. 1, 57, 280. "Mémoire sur la détermination des longueurs d'onde du Spectre solaire."

1868. Angström.-Upsala, 1868. Recherches sur le Spectre solaire.

18.1. Iitscheiner.-Ber. d. Wien. Acad. 63. Heft ii. p. 265. "Zur Bestinmung der W'ellenlänge der Fraunhofer'schen Linien."

1879. Peirce.-Am. Journ. Sci. [3] xviii. p. 51. "Note on the Progress of Experiments for comparing a Wave-length with a Metre."

1884. Thalén.-Upsala, 1885. Sur le Spectre du Fer obtenu a l'aide de lare étectrique, p. 18.

1886. Müller and Kempf.-Publicationen des Astrophysizalisehen Observatoriums zu Potsdam, จ. "Bestimmung der Wellenlänge von 300 Linien im Sonnenspectrum."

1886. De Lépinay.-Journ. de $1 \%$. [2] v. p. 411. "Détermination de la valeur absolue de la longueur d'onde de la raie $\mathrm{I}_{2}$."

1887. Bell.-Am. Jour. Sci. [3] xxxiii. p. 167; Phil. Mag. [5] xxiii. p. 265. "On the Absolute Wave-length of Light."

1887. Kurlbaum.-Berlin, 1887. Bestimmung der Wellenlänge einiger Fraunhofer'schen Linien.

In general the determination of absolute wave-length involves two quite distinct problems: first, the precise determination of some quantity which is an exact function of the wave-length and some other linear dimension; and, second, the reduction of this dimension to terms of some recognized standard of length. The first process can be made to give relative wave-lengths with a very high degree of accuracy, and is in nearly every case more exact than the second, which constitutes the main difficulty of the investigation. It is because the diffraction-grating lends itself readily to linear 
measurement that its use is preferable to the other interference methods, which involve usually the exact determination of a single very small linear quantity. The ingenious attempt of M. de Lépinay* to avoid this difficulty is interesting theoretically, but practically it involves a quantity even more uncertain than the average standard of length (the relation between the kilogramme and the metre), to say nothing of the experimental difficulties of the method. The angular measurements of nearly all the later investigators have been quite good enough to furnish very exact values of wave-length; but in every case it has been the measurement of the grating-space that has produced the manifold errors and discrepancies in the results. It has been the aim of the present research to investigate this fruitful source of errors, and, as far as possible, to avoid the difficulties springing from it.

In a previous paper $\dagger$ I briefly discussed the advantages of transmission- and reflexion-gratings. It only remains to add that further experience has convinced me that, not only are speculum-metal gratings far superior in brilliancy and sharpness of definition, but that it is possible, contrary to what one might suppose from their large coefficient of expansion, to rule them with almost perfect uniformity over a length as great as a decimetre. This large size, too, gives a great advantage in determining the grating-space; apart from the fact that speculum-metal has a coefficient of expansion not widely different from that of any one of the materials usually employed for standards of length, and that its temperature can be obtained with comparative ease.

\section{Methods and Instruments.}

The plane-grating can be used for wave-length measurement in a variety of ways, according to the preference of the investigator or the arrangement of the spectrometer. Five tolerably distinct methods may be enumerated. The general relation between the wave-length and the angles of incidence and diffraction is

$$
\lambda=s(\sin i+\sin (\phi-i)) \frac{1}{n} ;
$$

where $\lambda$ is the wave-length, $s$ the grating-space, $i$ and $\phi$ the angles of incidence and diffraction respectively, and $n$ the order of the spectrum observed. Making $i=0^{\circ}$, this at once

* Journ. Phys. [2] v. p. 411.

$\dagger$ Am. Journ. Sci. [3] xxxiii. p. 167; Phil. Mag. [5] xxiii. p. 266. 
becomes the ordinary formula

$$
\lambda=\frac{1}{n} s \sin \phi,
$$

which applies to the two methods of normal incidence; one in which the grating is kept accurately perpendicular to the collimator, the other in which it is kept perpendicular to the observing-telescope.

Next is the method used by Angström, in which $i$ is not reduced exactly to $0^{\circ}$, but measured and retained in the formula, the grating in this case being kept nearly perpendicular to the collimator. In this method a reading on the slit is necessary; and if $\alpha$ and $\alpha^{\prime}$ are the readings on the circle, and $M$ that on the slit, the working formulæ are:

$$
\frac{\alpha+\alpha^{\prime}}{2}-M=\delta \text { and } \frac{\alpha-\alpha^{\prime}}{2}=\phi ;
$$

then, if $i$ is, as before, the angle of incidence,

$$
\begin{aligned}
& \lambda=\frac{1}{n} s \sin \phi \cos (i+\delta), \\
& \sin i=\sin (i+\delta) \cos \phi, \\
& \tan i=\frac{\cos \phi}{1-\cos \phi} \delta .
\end{aligned}
$$

In the fourth method also $i$ is retained, but given a definite value. Putting the general formula in the form

$$
\lambda=\frac{1}{n} 2 s \sin \frac{\phi}{2} \cos \left(i-\frac{\phi}{2}\right),
$$

the deviation represented by the angular term will evidently be a minimum when $i=\frac{\phi}{2}$. If, then, one observes in the position of minimum deviation,

$$
\lambda=\frac{1}{n} 2 s \sin \frac{\phi}{2} .
$$

In the fifth method, collimator and observing-telescope are kept at a fixed angle with each other and the grating is turned. In this case, if $\phi$ is the angle of deviation, and $\theta$ the angle between the telescopes,

$$
\lambda=\frac{1}{n} 2 s \sin \phi \cos \frac{\theta}{2} \text {. }
$$

These methods are general, and the choice between them is simply a question of the convenient application of the apparatus at hand. Probably the first and second methods are 
the most generally useful, while the third is the most objectionable. The method of minimum deviation slightly increases the experimental difficulties, but often improves the definition of the gratings, and is capable of giving very exact results. The last method is applicable only when the spectrometer is so rigid as to ensure the permanence of the angle between the telescopes. When this condition is fulfilled, however, the method is very valuable, since it reduces the moving mass to a minimum and allows the method of repetition to be readily used.

In the present research, for the work with glass gratings, the second method was selected as best suited to the arrangement of the spectrometer. This was a very good instrument by Meyerstein. The circle is 32 centim. in diameter, divided on silver to $6^{\prime}$, and reading by two nicroscopes directly to $2^{\prime \prime}$ and by estimation easily to within $1^{\prime \prime}$. The collimating- and observing-telescopes are of 4 centim. clear aperture and about 35 centim. focal length, well corrected and firmly supported.

For the second part of the work, with speculum-metal gratings, it was desirable to use gratings of the largest size practicable, far larger than could be used on the abovedescribed instrument, both by reason of the small aperture of the telescope and the inability of the grating-holder to carry the requisite mass steadily. This part of the work was therefore carried out on a very large instrument, designed by Prof. Rowland especially for using gratings of the largest sizes as yet ruled. This instrument has virtually fixed telescopes, solidly clamped, with a small lateral range of adjustment, to a ' $\mathrm{I}$-shaped casting bedded in cement, which in turn forms the top of a large brick pier resting on a stone slab.

The telescopes are of 16.4 centim. clear aperture and about 2.5 metres focal length, and the objectives are of excellent quality. Each telescope is fastened to an arm of the T, which has a total length of over 2 metres, and bears at the extremity of the shaft the spectrometer proper. This is an instrument by Schmidt and Haensch, having a circle 32 centim. in diameter divided to $6^{\prime}$, and, as in the other spectrometer, reading by two microscopes directly to $2^{\prime \prime}$, and by estimation to less than half that amount. The original central platform had been removed and replaced by a grating-holder large enough to carry, if necessary, a 6 -inch grating. Such an apparatus limits one, of course, to the fifth method; but so rigid is the whole affair, that experience soon showed that the angle between the telescopes did not change by any appreciable amount. The circle, however, was not finely enough graduated, nor were the microscopes of sufficient power to 
derive the fullest benefit from the size of the telescopes ; over and over again has the line in the spectrum appeared slightly displaced from the crosshairs, when no difference whatever could be detected in the micrometer-readings. However, there was gained the great advantage of using gratings of a decimetre in length, giving spectra of great brilliancy and superb definition, and which could be measured with vastly greater exactness than is possible with the small gratings generally employed.

\section{Gratings.}

Four gratings have been used in my experiments-two of glass and two of speculum metal. The former are probably the best of the very few glass gratings that have been ruled on Prof. Rowland's engine. They are ruled on plane sextant mirrors of rather hard glass.

Grating I. contains 12,100 spaces in a length of very nearly thirty millimetres, the lines being nineteen millimetres long. It was ruled in Jan. 1884, at a temperature of $6^{\circ} .7 \mathrm{C}$.; gives spectra of excellent definition, quite free from ghosts or false lines, and having almost exactly the same focus on both sides of the normal.

Grating II. has 8600 spaces, with almost exactly the same length and breadth as I., is free from ghosts and false lines, and, like I., is very smoothly ruled, though it is somewhat inferior to $I$. in the matter of regularity. The definition is excellent, and the spectra alike in focus on both sides of the normal. It was ruled in Nov. 1884 at $11^{\circ} .6 \mathrm{C}$.

Gratings III. and IV. are on speculum metal. The plates are five inches square and five eighths of an inch thick, and were worked plane with especial care. The ruled surface is of the same size in each, four inches long by two inches length of lines.

Grating III. was ruled in April 1885, at a very nearly constant temperature of $10^{\circ} \mathrm{C}$. It contains 29,000 spaces, having very nearly the same grating-space as II. It is a phenomenal grating both in its superb definition and extraordinary regularity of ruling, and was selected from a large number because of its very unusual perfection. The focus of the spectra on each side of the normal is the same, and the ruling is flawless.

Grating IV. was ruled on the new dividing-engine just completed by Prof. Rowland, and was one of the first large ones completed. Although the new engine has even now not received the finishing touches, it has turned out a few gratings of remarkable excellence. One of these is IV., which was 
ruled in Dec. 1887, at a constant temperature of $17^{\circ} .2 \mathrm{C}$. It contain 40,000 spaces within the same dimensions as III., is equal to it in definition, and but very little inferior in regularity of ruling. It has very nearly the same focus on both sides of the normal, and the ruling is wonderfully even and perfect.

It should be noted that these four gratings are widely diverse, being ruled at different temperatures and under different conditions. I. and II. were ruled to widely diverse grating-spaces on different parts of the screw; III. was on speculum metal and with more than six times the ruled surface of I. or II. ; and finally IV. was ruled to a new gratingspace on a new dividing-engine. These differences may not favour close agreement in the experimental results, but they certainly serve to eliminate anything like systematic errors due to the gratings.

The above gives a general view of the gratings employed; but some further details will be mentioned in the second part of this paper in connexion with the determination of the grating-spaces.

\section{On the Standards of Length.}

Very many of the discrepancies in the determinations of absolute wave-lengths are the direct result of uncertainty in the standard of length employed. The cases of Angström and Van der Willigen have been already alluded to; and the same source of error is common to all other determinations. It seems, therefore, desirable to give at some length the various comparisons on which the wave-length as given by my experiments is based. Reserving for the present the actual measurement of the gratings, which is a comparatively simple matter, I will therefore discuss the standards directly employed, their relations to the Mètre des Archives as found by various comparisons, and finally the changes which have taken place in those relations since they were first determined.

The standards with which the gratings have been directly compared are two double decimetres on speculum metal, designated respectively $\mathbf{S}_{1}{ }_{1}$ and $\mathbf{S}_{2}{ }_{2}$. They were graduated and compared by Prof. W. A. Rogers in 1885 . The bar $S_{1}$ is $23 \mathrm{~cm}$. long, and bears near its edge the donble decimeter $\mathrm{S}^{\mathrm{a}}{ }_{1}$, subdivided to centimetres. The defining lines are less than $1 \mu$ in width and beautifully sharp and distinct. $S_{2}$ is $27 \mathrm{~cm}$. long, and is graduated in the same way, with lines of the same width. Both standards are of the same speculum metal, and are of very nearly the same mass, while the surfaces and graduation leave little to be desired. The 
coefficient of expansion of these bars was very thoroughly investigated by Prof. Rogers, and was found to be

\section{$17.946 \mu$ per metre per degree $\mathrm{C}$.}

The absolute lengths of $S^{a}$ and $S_{2}{ }_{2}$ depend on long series of comparisons with Prof. Rogers's bronze yard and metre $\mathbf{R}_{2}$ and steel copies thereof. Upon the relation existing between $\mathrm{R}_{2}$ and the Mètre des Archives depends, then, the absolute value assigned to the wave-length of light, since the close agreement of the various series of comparisons executed by Prof. Rogers between $R_{2}$ and the speculum-metal standards show that no sensible uncertainty exists in the relations between them.

The yard and metre $R_{2}$ is of the alloy known as Bailey's metal, this being the material of the Imperial Yard and many other standards. The graduations are upon platinum-iridium plugs, the polished faces of which are in the plane of one surface of the bar when supported at its neutral points. The relation of the metre $R_{2}$ to the Mètres des Archives rests on a very large number of comparisons made with two entirely independent secondary standards; the copper metre designated $\mathrm{T}$, and the brass yard and metre designated C.S. A full account of these comparisons is contained in rol. xviii. of the Proceedings of the American Academy of Arts and Sciences.

The metre $\mathrm{T}$ is on platinum plugs in a pure copper bar and was traced and compared by M. Tresca in 1880, from the Conservatoire line-metre No. 19, the relation of which to the Mètre des Archives was very exactly known.

The yard and metre C.S. has its graduations on silver plugs in a brass bar. The yard was compared directly with the Imperial Yard in 1880, and the standard was then sent to Breteuil, where it was compared with the International Metre by Dr. Pernet.

There were thus two completely independent sources from which the relation of $R_{2}$ to the Mètre des Archives could be obtained. The results derived by very elaborate comparisons with each of these were as follows:-

$$
\left.\begin{array}{ll}
\text { From T } & \mathrm{R}_{2}-\mathrm{A}_{0}=+1 \cdot 5 \mu \\
\text { From C.S. } \mathrm{R}_{2}-\mathrm{A}_{0}=+1 \cdot 1 \mu
\end{array}\right\} \text { at } 16^{\circ} \cdot 67 \mathrm{C} .
$$

where $A_{0}$ is the Metre des Archives. In addition to the very close agreement of the above, further evidence was obtained by deriving the relation between the yard and metre from $R_{2}$, the yard $R_{2}$ having been exactly determined by 
comparisons with C.S. and with "Bronze 11," one of the primary copies of the Imperial Yard, which had been recompared with that standard in 1878.

From the comparisons of $S_{1}$ and $S_{2}$ made in 1885 the following values of those standards were deduced:-

$$
\begin{aligned}
& \mathrm{Sa}_{1}+0 \cdot 98 \mu=\frac{1}{5} \mathrm{~A}_{0} \text {, and } \\
& \mathrm{Sa}_{2}+0 \cdot 2 \mu=\frac{1}{5} \mathrm{~A}_{0} .
\end{aligned}
$$

Hence

$$
\mathrm{S}_{2}=\mathrm{S}_{1}^{\mathrm{a}}+0 \cdot 78 \mu \text {; }
$$

and for the first decimetre were found the relations:-

\section{Whence}

$$
\begin{aligned}
& \mathrm{Dm}_{1} \mathrm{~S}_{1}+0 \cdot 05 \mu=\frac{1}{10} \mathrm{~A}_{0}, \\
& \mathrm{Dm}_{1} \mathrm{~S}_{2}{ }_{2}-0.01 \mu=\frac{1}{10} \mathrm{~A}_{0}, \\
& \mathrm{Dm}_{1} \mathrm{Sa}_{2}=\mathrm{Dm}_{1} \mathrm{~S}_{1}+0.06 \mu .
\end{aligned}
$$

On these equations were based the results embodied in my former paper. In the latter part of May 1887, these standards were very carefully compared with each other, and with a speculum-metal bar graduated by Prof. Rowland, as I desired to take one or more of the standards to Berlin during the summer in order to get a comparison with the standard used by Müller and Kempf.

The results of this examination were of a somewhat startling character, as follows:-

$$
\begin{aligned}
& \mathrm{Sa}_{2}=\mathrm{Sa}_{1}+1 \cdot 2 \mu, \text { direct, } \\
& \mathrm{Sa}_{2}=\mathrm{S}_{1}+1 \cdot 1 \mu, \text { through the Rowland bar }
\end{aligned}
$$

designated $\mathbf{R}_{\mathrm{B}}$. Also,

$$
\mathrm{Dm}_{1} \mathrm{~S}_{2}=\mathrm{Dm}_{1} \mathrm{~S}_{1}+1 \cdot 7 \mu \text {, through } \mathrm{R}_{\mathrm{B}} \text {. }
$$

In 1885 Rogers had found for the relation between the two decimetres of each bar:-

$$
\begin{aligned}
& \mathrm{Dm}_{2} \mathrm{~S}^{\mathrm{a}}=\mathrm{Dm}_{1} \mathrm{Sa}_{1}-0.56 \mu, \\
& \mathrm{Dm}_{1} \mathrm{~S}_{2}=\mathrm{Dm}_{2} \mathrm{Sa}_{2}+0.46 \mu .
\end{aligned}
$$

I now found for the same quantities:-

$$
\begin{aligned}
& \mathrm{Dm}_{2} \mathrm{~S}^{\mathrm{a}}=\mathrm{Dm}_{1} \mathrm{~S}_{1}{ }_{1}+0 \cdot 64 \mu, \text { direct, } \\
& \mathrm{Dm}_{2} \mathrm{~S}^{\mathrm{a}_{1}}=\mathrm{Dm}_{1} \mathrm{~S}^{\mathrm{a}_{1}}+0.60 \mu, \text { from } \mathrm{R}_{\mathrm{B}}, \\
& \mathrm{Dm}_{1} \mathrm{~S}_{2}=\mathrm{Dm}_{2} \mathrm{~S}_{2} \mathrm{~s}_{2}+60 \mu, \text { direct, } \\
& \mathrm{Dm}_{1} \mathrm{Sa}_{2}=\mathrm{Dm}_{2} \mathrm{~S}_{2}+1 \cdot 65 \mu, \text { from } \mathrm{R}_{\mathrm{B}} .
\end{aligned}
$$

All these relations being for $16^{\circ} .67 \mathrm{C}$.

The standard $\mathbf{S}_{2}$ was taken to Berlin during the summer; and through the kindness of Dr. Nieberding, Director of the Normal Aichungs Commission, I was enabled to have it compared with $R_{78}$, the standard metre to which the wave-length 
measurements of Müller and Kempf, and Kaulbaum had been referred. From this comparison was derived the relation:-

$$
\mathrm{S}_{2}^{\mathrm{a}}-1 \cdot 68 \mu( \pm 0 \cdot 15 \mu)=\frac{1}{5} \mathrm{~A}_{0} .
$$

On returning to Baltimore, the first step was to redetermine the length of $\mathrm{S}_{2}$. A series of comparisons was therefore instituted between it and the steel yard and metre $\mathrm{A}_{4}$, the relation of which to $R_{2}$ was accurately known, $A_{4}$ having been traced and determined by Prof. Rogers, and furnished by him to the Johns Hopkins University. Only half of this standard is subdivided to decimetres; but a series of comparisons with the various pairs of decimetres gave the relation

$$
\mathrm{S}_{2}+1 \cdot 3 \mu=\frac{1}{5} \mathrm{~A}_{0} \text {. }
$$

This result taken together with the relations found between $S_{1}^{a}$ and $S_{2}^{a}$ made it tolerably clear that a change had taken place in the speculum-metal standards; and to obtain a further confirmation, Prof. Rogers kindly consented to give them a rigid examination and again compare them with all attainable accuracy to $R_{2}$. His results for $\mathrm{S}_{2}$ were as follows:-

$$
\begin{gathered}
\mathrm{Dm}_{1} \mathrm{~S}_{2} \mathrm{a}_{2}=\mathrm{Dm}_{2} \mathrm{~S}_{2}+1 \cdot 70 \mu, \\
\mathrm{S}_{2}^{\mathrm{a}}+1 \cdot 0 \mu=\frac{1}{5} \mathrm{~A}_{0} .
\end{gathered}
$$

There is no escape from the conclusion, therefore, that the speculum-metal bars $S_{1}$ and $S_{2}$ have changed both in absolute length and the relative lengths of their parts. Here are two bars of the same shape, mass, material, and constant of expansion. Each had the relation between its halves determined in the early part of 1885 . Two years later these relations are found to have changed by at least $1 \mu$; and an independent determination by the original observer confirms this result in the most unequivocal way. Further, the original observer recompares one of these standards with the standard from which it was originally determined, and finds a change of $1 \mu$.

It should be borne in mind that with the comparator used by me in this work, $1 \mu$ is completely outside of any possible errors of observation. The microscope used was especially made for micrometric work, and has a power of two hundred and fifty diameters, while one division of the micrometer equals $0 \cdot 28 \mu$. The average error of a single comparison between two decimetres is rarely greater than $0^{\circ} 1 \mu$, while the temperature of the observing vault can be kept for several days constant within $0^{\circ} .5 \mathrm{C}$., and during a day's observations 
usually remained constant within half that amount. The bars under comparison were side by side, symmetrically placed with reference to the illumination, and were at temperatures very near to $16^{\circ} \cdot 67$, at which they were standard.

The facts, then, concerning the speculum-metal bars are these :-In about two and a half years $\mathrm{S}_{2}{ }_{2}$ has shortened by very nearly $1 \cdot 0 \mu$ and $S^{a}$ by a little over that amount. In $\mathrm{Sa}_{2}$ this change has taken place exclusively in the last decimetre, and in $\mathrm{S}^{\mathfrak{a}}{ }_{1}$ it has been confined to the first decimetre.

The apparent slight increase in $\mathrm{Dm}_{1} \mathrm{~S}_{2}$ and $\mathrm{Dm}_{2} \mathrm{~S}^{\mathrm{a}}{ }_{1} \mathrm{I}$ do not regard as beyond the effect of the experimental errors. The changes in the lengths of the subdivisions of these standards are very curious, and some explanation may be offered by the fact that the bars were cast in a nearly vertical position and annealed in sawdust, a method hardly sufficient for a material so strongly crystalline as speculum metal. I think, however, one is justified in drawing the conclusion that speculum metal, so tempting on account of its beautiful surface and the exquisite sharpness of the graduations drawn upon it, is a material thoroughly unsuitable for standards of length by reason of its tendency to change with time. I have thus entered into somewhat minute details in the case of these bars, because the whole question of changes in standards of length is in a somewhat unsettled state, and it seems desirable to put on record this case, which has been investigated with more than ordinary care by both Prof. Rogers and myself, and in which the changes found have taken place within a comparatively short time.

It is quite well known that in 1855 this question was raised by Mr. Sheepshanks, then engaged in constructing the new British standards. Discrepancies amounting sometimes to 2 or $3 \mu$ appeared in his measurements; but after a considerable amount of study, these differences appeared to be too irregular to be fairly ascribable to actual changes. Slight variations of temperature, especially when the standards compared were of different materials, the lagging of the real temperatures of the bars behind the thermometer indications, and particularly the effect of coarse and sometimes unsymmetrical defining lines, are perhaps enough to account for the observation.

The work, however, done on the U.S. bar "Bronze 11," as reported in the report of the Coast Survey for 1877, seems to show genuine change in that standard.

A long series of comparisons with the Imperial Yard and its copies in 1878 , showed systematically a shortening relative to the Imperial Yard of over $4 \mu$. Although further measure- 
ments have tended to somewhat lessen this discrepancy, it seems to be sufficient, considering the fact that "No. 11 ", and the Imperial Yard are of the same shape, material, and mass, and were compared on the same apparatus as during the original comparisons in 1857 , and at nearly the standard temperature, to establish the fact of a real change. While 3 or $4 \mu$ is absolutely a small quantity, its systematic appearance under conditions almost identical with those of the original measurement can hardly be ascribed to experimental errors. The other cases cited in the above-mentioned paper tend to confirm this conclusion.

The gradual and sometimes very irregular changes that are known to take place in both the bulbs and stems of thermometers would lead one to expect that glass standards of length would be liable to similar changes, though probably far less in amount. It was, therefore, with special interest that $I$ examined glass Decimetres III. and IV. belonging to the Coast Survey, and used by Peirce in his wave-length measurements. These scales are on plate glass, of the same dimensions, and having coefficients of expansion not widely different. A series of comparisons made at a nearly constant temperature of $16^{\circ} .5$ C. gave the direct relation

$$
\text { III. }=\text { IV } .+2 \cdot 1 \mu \text {. }
$$

While the same relation deduced from Peirce's direct comparison, by applying the coefficients of expansion assigned by him, is

$$
\text { III. }=\text { IV. }+1 \cdot 3 \mu \text {. }
$$

The defining-lines on both standards are fine and sharp; and unless Peirce's coefficients are grossly in error, the evidence of change between 1879 and 1887 is very strong indeed.

Having now the exact present relation of $\mathrm{S}_{2}{ }_{2}$ to the original standard $R_{2}$, it remained only to investigate the difference between this result and the length of $\mathrm{S}_{2}$ as deduced from the Berlin comparisons. I have been unable to obtain the details concerning $R_{78}$, the standard used in these comparisons, but it was determined by comparison with the standard metre of the International Bureau. The comparisons of $\mathrm{S}_{2}{ }_{2}$ with $\mathrm{R}_{78}$ were carefully made by two observers, and it is probable that the result represents the relation between these standards with considerable exactness. It should, however, be borne in mind that the microscopes had each a power of only 50 diameters, and that the bars in question are of very different material and mass, thus giving a chance for small errors due to varying temperature.

Phil. Mag. S. 5. Vol. 25. No. 155. April 1888. 
It is possible, however, to check this result by referring $\mathrm{S}_{\mathbf{a}}{ }_{2}$ to the Berlin platinum standard through the medium of the Coast Survey metre "No. 49." This latter standard was compared in 1876 with metre 1605 and directly with the platinum metre. The details are given in Prof. Foerster's report contained in the Report of the Coast Survey for 1876. The result of the direct comparison was

$$
\mathrm{Pl}-" 49 "=+24 \cdot 4 \mu \text {. }
$$

But now Prof. Rogers has compared $R_{2}$ with " 49 ," obtaining in terms of the assumed length of $R_{2}$

$$
\text { " } 49 "=\mathrm{A}-19 \cdot 3 \mu \text {; }
$$

the assumed value of $R_{2}$ was

Hence we have

$$
\mathrm{R}_{2}=\mathrm{A}+1 \cdot 3 \mu \text {. }
$$

from which follows

$$
\mathrm{R}_{2}-" 49 "=20 \cdot 6 \mu \text {, }
$$

$$
\mathrm{PI}-\mathrm{R}_{2}=3 \cdot 8 \mu \text {. }
$$

If now the equation between $\mathrm{Pl}$ and the Metre des Arehives established by direct comparison in 1860 be correct,

And therefore

$$
\mathrm{A}_{0}-\mathrm{Pl}=-3 \cdot 01 \mu \text {. }
$$

$$
\mathrm{R}_{2}-\mathrm{A}_{0}=-0 \cdot 8 \mu,
$$

a result which is in close accordance with those derived from the Conservatoire metre and Type $I$. of the International Bureau by means of the Standards T. and C.S.

In my final determination of wave-length, I have used the mean value of $\mathrm{S}_{2}{ }_{2}$ as derived by the foregoing methods. Collecting equations,

$$
\begin{array}{lll}
\mathrm{S}_{2}^{\mathrm{a}}+0^{\mu} \cdot 96=\frac{1}{5} \mathrm{~A}_{0} . & \text { From T. } \\
\mathrm{S}_{2}^{\mathrm{a}}+1^{\mu \cdot} \cdot 04=\frac{1}{5} \mathrm{~A}_{0} . & \Rightarrow & \text { C.S. } \\
\mathrm{S}^{\mathrm{a}}+1^{\mu \cdot} \cdot 40=\frac{1}{5} \mathrm{~A}_{0} . & \Rightarrow & \text { “49." } \\
\mathrm{S}_{2}^{\mathrm{a}}-1^{\mu} \cdot 68=\frac{1}{5} \mathrm{~A}_{0} . & \Rightarrow & \mathrm{R}_{78} .
\end{array}
$$

Giving to the equations derived from C.S. and $R_{78}$ twice the weight of the others, we have finally,

$$
\mathrm{S}_{2}^{\mathrm{a}}+0^{\mu} \cdot 27=\frac{1}{5} \mathrm{~A}_{0} \text {. }
$$

$I$ have given the relations derived from C.S. and $R_{78}$ double weight because these standards have been compared directly with the standard of the International Bureau, which now, probably, should be regarded as the ultimate standard of 
reference. Especially is this true, since it is rumoured, apparently not without foundation, that the Mètre des Archives is at present, for some unassigned reason, undesirable as a direct standard of reference.

It is unfortunate that there is not more general uniformity in the material, shape, and mass of standards of length. Difference in these particulars are fruitful sources of error in comparisons, and when one adds to this the trouble arising from bad defining-lines and imperfect focus, the wonder is that the results are as good as they usually are. It is hard to say what material is least liable to changes, but it is quite certain that substances of crystalline structure, and alloys of which the physical properties are largely dependent on a nearly definite composition, should be avoided. Probably pure platinum, silver, and copper, annealed with the utmost care, and kept for some years before final graduation, are less likely to change than any other material which we know. For short standards, possibly bars of native copper, prepared with as few strains as possible, would give the closest possible approximation to a material which has arrived at a permanent state.

Physical Laboratory, Johns Hopkins University, Feb. 22, 1888.

XXXI. Observations on the Height, Length, and Velocity of Ocean Waves. By Hon. Ralph Авеrсromby, F. R. Met. Soc.*

$T$ THE interest in ocean waves has so much declined in recent years, that physicists have perhaps scarcely realized how much more easily measurements can be taken now than formerly.

In the old days wave-heights could only be ascertained, more or less, by estimation; while the length and speed could only be determined by a common watch. Now-a-days the aneroid can easily measure small vertical heights to within one or two feet; while the fly-back chronograph enables time to be measured to the 1 th second, without taking the eye for one moment off the object to be watched.

The following observations were taken on board the S.S. 'Tongariro,' in various parts of the S. Pacific between New Zealand and Cape Horn, in the month of June 1885.

Height was measured by a $4 \frac{1}{2}$-inch aneroid with a very

- Communicated by the Physical Society: read February 25, 1888. 